\title{
THE RATE OF OXIDATION OF FERROUS SALTS BY CHROMIC ACID
}

\section{BY CLARA C. BENSON}

In 1858 Schönbein ${ }^{1}$ announced that when dilute chromic acid is mixed with a dilute solution of potassium iodide and starch paste, the mixture turns blue very slowly; but that the blue color appears immediately on shaking with platinum moss or with fine iron powder, or on adding a few drops of the dilute solution of a ferrous salt. At the present time the subject of catalysis is attracting a good deal of attention; and as our knowledge of this particular instance - one of the most striking yet met with - is limited to the discoveries of Schönbein, it was suggested by Prof. W. Lash Miller that I should study the reaction between ferrous salts, iodides, and chromic acid, in the light of the prevalent theories of chemical kinetics.

The present paper contains a portion of the results already obtained, viz: those of experiments on the reaction between chromic acid and ferrous sulphate in the absence of iodides. In addition to the measurements here published, I have carried out a number of experiments on the rate of liberation of iodine in solutions containing chromic acid, potassium iodide, and ferrous salts, and on the rate of oxidation of the ferrous salt in the same mixtures; when completed, these measurements will form the subject of a second conmunication. Theoretical discussions have been postponed until all the results are published.

My first experiments showed that the accelerating influence exerted by the ferrous salts is not shared by ferric salts. ${ }^{2}$ If the chemicals, properly diluted, be mixed in the order-chromic acid, ferrous salt, starch, potassium iodide (with a pause to allow

${ }^{1}$ Pogg. Ann. 105, 265 (1855). The concentrations are given.

2 Unpublished experiments by Mr. W. C. Bray show that when chloric acid is used in place of chromic acid, ferrous and ferric salts exert about the same influence on the rate. 
of the oxidation of the ferrous salt before the iodide is added) no sudden appearance of the blue color is observed; while if Schönbein's order - chromic acid, potassium iodide, starch, ferrous salt - be adhered to, the blue color appears immediately upon addition of the ferrous salt.

This raises the question whether, after all, the action of the iron can be regarded as truly "catalytic", and not rather as resembling the action of aluminium chloride in Friedel and Craft's synthesis, or that of sodium ethylate in the preparation of acetacetic ether and similar substances; I hope that the results of my experiments may furnish a definite answer to this question.

\section{Method of analysis}

I experienced great difficulty in devising a method for determining the amount of ferrous salt present in solutions containing potassium bichromate, sulphuric acid, and ferrous and ferric sulphates.

The first method experimented with consisted in adding to the mixture a known quantity of potassitum permanganate, which instantly oxidized the ferrous sulphate. The excess of permanganate - and thus by difference the ferrous sulphate was determined by adding potassium iodice, and estimating the iodine set free. It soon appeared, however, that in many cases the reduction of the permanganate by the iodide was incomplete; and as the means taken to overcome this difficulty - addition of acid, heating, letting stand - brought about oxidation of the iodide by the chromic acid, I was driven to abandon the method.

An attempt was then made to measure the cliange in the acidity of the solution caused by the reaction

$$
\begin{aligned}
& \mathrm{K}_{2} \mathrm{Cr}_{2} \mathrm{O}_{7}-7 \mathrm{H}_{2} \mathrm{SO}_{4}+6 \mathrm{FeSO}_{4}= \\
& \mathrm{K}_{2} \mathrm{SO}_{4}+\mathrm{Cr}_{2}\left(\mathrm{SO}_{4}\right)_{3}+{ }_{3} \mathrm{Fe}_{2}\left(\mathrm{SO}_{4}\right)_{3}+{ }_{7} \mathrm{H}_{2} \mathrm{O} \text {, }
\end{aligned}
$$

but without siccess. Even if a suitable indicator had been discovered, the method would hardly have proved accurate in the presence of a large initial excess of acid. Analysis by electrical conductivity is excluded for the same reason.

Colorimetric analysis was interferred with by the presence 
of the bichromate and the ferric salts; and the method which promised most, determination of the ferric salt by potassium sulphocyanate, was excluded by the fact that, as will appear later, the rate measurements had to be carried out in presence of a large excess of ferric salt.

In the end I found a means of determining the quantity of ferrous salt present by measuring its catalytic effect on the rate of oxidation of potassium iodide by chromic acid; thus the reaction whose study forms the subject of this research furnished the only available method of analysis.

The experiments were carried out in the following manner: (A) To $500 \mathrm{cc}$ of a solution containing measured quantities of acid, bichromate, and ferric salt, ${ }^{,}$there was added roo $\mathrm{cc}$ of a solution containing a known amount of ferrous sulphate, and the time was noted. After a suitable interval, roo cc of a dilute solution of potassium iodide was added and the time noted again. After a further period of four minutes the reaction was stopped, and the free iodine determined. In the earlier experiments the iodine was determined by sodium thiostrlphate, the reaction being slowed sufficiently for the purpose by the addition of sodium acetate and tartrate; this method fails however in the presence of large quantities of iron, and ultimately I replaced the thiosulphate by sodium arsenite, and the acetate and tartrate by ammoninm bicarbonate. ${ }^{2}$

In order to interpret the restults so obtained, and from the amount of iodine liberated in the second part of the experiment to determine the amount of ferrous salt remaining at the end of the first part, a series of experiments were carried ont, employing the same chemicals in the same quantities, but mixing them in a different order, as follows: -

(B) $500 \mathrm{cc}$ of a solution containirg acid, chromate, ferric salt, and part of the ferrous salt (which is promptly oxidized):

${ }^{1}$ Or oxidation product, see page 5 .

2 Carbon dioxide was passed into a saturated solution of ammonium carbonate until no smell of ammonia was noticeable, the solution was filtered and its own volume of water added. Io ce of this half saturated solution were used in each titration; the same reading was obtained when $20 \mathrm{cc}$ were used. 
too $\mathrm{cc}$ of the dilute solution of potassium iodide (no liberation of iodine takes place), then the remainder of the ferrous salt ("part two") dissolved in $100 \mathrm{cc}$ water. After an interval of four minutes the reaction was stopped by addition of ammonium bicarbonate, starch was added and the iodine determined by sodium arsenite. The results of a set of experiments of series $B$ were plotted, using "iodine liberated" and "ferrous salt part two" as coordinates, and by means of the curve so obtained the amount of ferrous sulphate remaining in experiment $A$ at the moment of adding the potassium iodide was determined.

This method of determining the ferrous salt involves no assumption as to the laws under which iodine is liberated in the second part of experiment $A$; but the fact that the amount of iodine set free during the four minutes is roughly proportional to the amount of ferrous salt present at the beginning of that time, is of great assistance in the practical application of the method.

\section{Details of the Operations}

The solutions were kept in wash-bottles clamped to shelves in a large vessel containing ice and water, well stirred. The requisite quantities were blown out into measuring flasks and mixed in a beaker supported in the bath. The ferrous sulphate and the potassium iodide respectively were poured in quickly from Nessler tubes, the cuntents of the beaker being stirred meanwhile; the mixing was complete in about $t / 5$ or $2 / 5$ seconds. Time was taken with a stop-watch.

Owing to the presence of ferric hydrate (as a flocky precipitate, or as a colloidal suspension in the liquid), special precantions had to be taken in determining the iodine by sodium arsenite. Accurate results were obtained only when the arsenite was dropped in very slowly (I minute for I cc I/IOO normal arsenite), the solution being vigorously stirred meanwhile by a small motor. When the blue color of iodide of starch had disappeared, a few drops of an equivalent iodine solution were used to titrate back; with practice the end point could be determined within one or two drops, although the solution was colored by the chromate, its volume was large, and the reading was further 
interfered with by the presence of the ferric hydrate. Blank experiments showed that when the analysis was carried out in the manner described, the presence of iron had no effect on the result.

\section{Solutions}

A solution of potassium bichromate was made by dissolving a weighed quantity of the salt; this formed the standard solution with which the others were compared. The strength of a solution of sulphuric acid was determined by titrating both it and the bichromate against a solution of potash, with phenolphthalein as indicator. A solution of ferrous sulphate free from ferric salt ${ }^{x}$ (no color with ammonium sulphocyanate) was prepared and kept under carbon dioxide in a filter bottle; its titre was determined against the standard bichromate. The "product of oxidation" was made by mixing equivalent quantities of bichromate, acid, and ferrous sulphate.

Before using, these solutions were diluted, the compositions of the solutions being as follows:

Bichromate, $0.000827 \mathrm{~mol}_{2} \mathrm{Cr}_{2} \mathrm{O}_{\text {; }}$ per liter.

Acid, $0.00498 \mathrm{~mol} \mathrm{H}_{2} \mathrm{SO}_{4}$ per liter.

Ferrous sulphate, $0.0472 \mathrm{~mol} \mathrm{FeSO}_{4}$ per liter.

Oxidation product, $5 \mathrm{cc}$ of the ferrous sulphate were used in making $50 \mathrm{cc}$.

Thus in the reaction

$$
\mathrm{K}_{2} \mathrm{Cr}_{2} \mathrm{O}_{7}+6 \mathrm{FeSO}_{4}+{ }_{7} \mathrm{H}_{2} \mathrm{SO}_{4}==+\mathrm{Kr}_{2}\left(\mathrm{SO}_{4}\right)_{3}+{ }_{3} \mathrm{Fe}_{2}\left(\mathrm{SO}_{4}\right)_{3}+{ }_{7} \mathrm{H}_{2} \mathrm{O} \text {, }
$$

I cc of the ferrous solution is equivalent to $9.57 \mathrm{cc}$ of the bichro. mate, and II cc of the acid.

\section{Plan of the experiments}

The plan adopted is one which has proved successful in a

${ }^{1}$ Commercial ferrous sulphate was dissolved in hot water, boiled and fil. tered. To the filtrate a little barium carbonate was added and the mixture again boiled, cooled in a vacuum, and the flask filled with carbon dioxide, a portion of the solution analyzed, and then the remainder filtered through a siphon into a measuring flask (filled with carbon dioxide) containing the calculated amount of air-free water. 
number of investigations recently carried out in this laboratory; the quantity of one of the reagents (here the ferrous salt) being kept much less than those of the others, the concentrations of the latter remained practically unaltered during the reaction, and the "order of the reaction" with respect to the ferrous salt was readily determined. ${ }^{1}$ It was however not possible to determine the order of the reaction with respect to the bichromate and to the acid in the same way (viz., by carrying out experiments in which the concentrations of these two substances respectively were kept low); but by simply doubling, trebling, etc., the concentration of the acid or bichromate while still keeping that of the ferrous salt comparatively small, the influence of the former on the rate was easily determined.

\section{Influence of the ferrous salt on the rate}

Table I. $a$ gives the results of a series of experiments carried out with a mixture of $\mathrm{I} 00 \mathrm{cc}$ of the acid, $200 \mathrm{cc}$ of the bichromate solution, $50 \mathrm{cc}$ of the "oxidation product" and I cc of the ferrous sulphate, ${ }^{2}$ the volume being made up to 600 cc with water. Under $\theta$ is given the time in minutes between the addition of the ferrous salt and that of the potassium iodide, and under $A s$ the volume of potassiun arsenite solution equivalent to the iodine liberated in the second part of the experiment.

Table I. $b$ contains the blank experiments by means of which the values of $A-x$ obs (amount of ferrous salt remaining at the expiration of $\theta$ minutes) in Table I. $a$ are calculated. Under $k_{1}$, $k_{2}, k_{3}$, finally, are the values of the constants calculated on the assumptions that the rate $(d x d \theta)$ is proportional to the first, second, or third power of $A-x$ respectively.

Tables II. $a$ and II. $b$ comprise similar measurements in which the initial concentration of the ferrous sulphate was onehalf that in Table I. It will be seen that the values of $k_{2}$ remann constant thronghont the tables, while those of $k_{1}$ and $k_{3}$ vary. The reaction is thus of the second order with respect to the ferrous

${ }^{1}$ Ostwald's "Method of Isolation," Lehrbuch, 2 E, i., II. 2; pg. 238

2 The diluted solutions whose compositions are given on page 5 were used. 
TABLE I. $a$

$\mathrm{H}_{2} \mathrm{SO}_{4} 100 \mathrm{cc}, \mathrm{K}_{2} \mathrm{Cr}_{2} \mathrm{O}_{i} 200 \mathrm{cc}$, Ox. prod. $50 \mathrm{cc}, \mathrm{FeSO}_{4}$ I cc, Vol. 600 cc. $^{\mathrm{r}}$

\begin{tabular}{lc:cccc|c|c}
$\theta$ & As & $\begin{array}{c}\text { A-x } \\
\text { obs. }\end{array}$ & $k_{1}$ & $k_{2}$ & $k_{3}$ & $\begin{array}{c}\text { A-x } \\
\text { calc. }\end{array}$ & Diff. \\
\hdashline 0.0 & 4.42 & I.O & - & - & - & $(\mathrm{I} .0)$ & - \\
0.5 & 3.35 & 0.76 & $0.1 \mathrm{I}$ & 0.63 & $\mathrm{I} .43$ & $0.74+0.02$ \\
1.0 & 2.60 & 0.59 & 0.12 & 0.69 & 1.86 & 0.59 & 0.0 \\
1.5 & 2.25 & $0.5 \mathrm{I}$ & 0.10 & 0.64 & 2.34 & 0.49 & +0.02 \\
2.25 & 1.75 & 0.39 & 0.09 & 0.69 & 2.48 & 0.39 & 0.0
\end{tabular}

TABLE I. $b$

\begin{tabular}{llll|l}
\hline $\mathrm{FeSO}$, & 1.0 & 0.6 & 0.5 & 0.0 \\
$\mathrm{As}$ & 4.42 & 2.70 & 2.15 & 0.0
\end{tabular}

TABLE II. $a$

$\mathrm{H}_{2} \mathrm{SO}_{4} 100 \mathrm{cc}, \mathrm{K}_{2} \mathrm{Cr}_{2} \mathrm{O}_{7} 200 \mathrm{cc}$, Ox. prod. $50 \mathrm{cc}, \mathrm{FeSO}_{4} 0.5 \mathrm{cc}$, Vol. 600 cc. $^{1}$

\begin{tabular}{cccc|cccc}
$\theta$ & As & $\begin{array}{c}\text { A } \\
\text { obs. }\end{array}$ & $k_{1}$ & $k_{2}$ & $k_{3}$ & $\begin{array}{c}\text { A }-x \\
\text { caic. }\end{array}$ & Diff. \\
\hline 0.0 & 2.55 & 0.50 & - & - & - & $(0.50)$ & - \\
1.0 & 1.93 & 0.37 & 0.13 & 0.70 & 3.3 & 0.37 & 0.0 \\
2.0 & 1.55 & 0.29 & 0.12 & 0.72 & 3.9 & 0.29 & 0.0 \\
3.0 & 1.30 & 0.24 & 0.11 & 0.72 & 4.5 & 0.24 & 0.0
\end{tabular}

TABLE II. $b$

$\begin{array}{ll:lll}\mathrm{FeSO} & 0.5 & 0.3 & 0.2 & 0.0 \\ \mathrm{As} & 2.55 & 1.60 & 1.10 & 0.0\end{array}$

${ }^{1}$ In the experiments of Tables 1 . and II. the acid was slightly stronger than in the others. See Table VI. 
salt, a conclusion which is in accordance with my subsequent experiments.

Under the headings " $A-x$ calc" in Tables I. $a$ and II. $a$ are entered the values $A-x$ obtained from $\theta$ and $A$ by means of the equation

$$
0.70 \theta=\mathrm{I} /(A-x)-\mathrm{I} / A .
$$

The difference between $A-x$ calc and $A-x$ obs ("Diff"), is well within the errors of experiment.

\section{Influence of the acid on the rate}

In the experiments of Tables III., IV. and V. the amount of potassium bichromate in the solutions was equivalent to ten times the amount of ferrous salt initially present; thus the changes which the concentration of the former underwent during the reaction were not great, while on the other hand it was possible, without unduly increasing the speed of the reaction, to vary the concentration of the acid from five molecules of acid for one of bichromate in Table III. to ten molecules acid for one of bichromate in Table V. By thus keeping the molecular concentration of the acid much greater than that of the bichromate it was hoped that the influence of change of dissociation of the chromic acid on the rate would be eliminated.

TABLE III. $a$

$\mathrm{H}_{2} \mathrm{SO}_{4}$ IOO cc, $\mathrm{K}_{2} \mathrm{Cr}_{2} \mathrm{O}_{7}$ IOO cc, Ox. prod. $50 \mathrm{cc}, \mathrm{FeSO}_{4}$ I cc,

Vol. $600 \mathrm{cc}$.

\begin{tabular}{l|llll}
\hline$\theta$ & 0.0 & 1.0 & 2.0 & 4.0 \\
As & 2.25 & 1.75 & 1.40 & 1.15 \\
A $-x$ & 1.0 & 0.82 & 0.68 & 0.56 \\
$k_{2}$ & - & 0.22 & 0.24 & 0.20
\end{tabular}

TABLE III. $b$

$\begin{array}{lllll} & & & \\ \mathrm{FeSO}_{4} & 1.0 & 0.7 & 0.5 & 0.0 \\ \mathrm{As} & 2.25 & 1.55 & \text { I.00 } & 0.0\end{array}$


TABLE IV.a

$\mathrm{H}_{2} \mathrm{SO}_{4}$ i $50 \mathrm{cc}, \mathrm{K}_{2} \mathrm{Cr}_{2} \mathrm{O}_{i}$ too cc, Ox. prod. $50 \mathrm{cc}, \mathrm{FeSO}_{4}$ I cc, Vol. $600 \mathrm{cc}$.

\begin{tabular}{l|llll}
$\theta$ & 0.0 & 1.0 & 2.0 & 4.0 \\
$\mathrm{As}$ & 4.95 & 3.40 & 2.75 & 1.80 \\
$\mathrm{~A}-x$ & 1.0 & 0.66 & 0.53 & 0.33 \\
$k_{2}$ & - & 0.50 & 0.45 & 0.50
\end{tabular}

TABLE IV. $b$

$\begin{array}{lllll} & & & & \\ \mathrm{FeSO}_{1} & 1.0 & 0.7 & 0.4 & 0.0 \\ \mathrm{Ass} & 4.95 & 3.55 & 2.35 & 0.0\end{array}$

TABLE V.a

$\mathrm{H}_{22} \mathrm{SO}_{4} 200 \mathrm{cc}, \mathrm{K}_{2} \mathrm{Cr}_{2} \mathrm{O}_{i} 100 \mathrm{cc}, \mathrm{Ox}$. prod. $50 \mathrm{cc}, \mathrm{FeSO}_{4}$ I cc, Vol. $600 \mathrm{cc}$.

$\begin{array}{llllll}\theta & 0.0 & 0.5 & 1.0 & 2.0 & 4.0 \\ \mathrm{As} & 7.95 & 5.65 & 4.45 & 3.15 & 2.10 \\ \mathrm{~A}-x & 1.0 & 0.69 & 0.54 & 0.37 & 0.25 \\ h_{2} & - & 0.90 & 0.85 & 0.85 & 0.75\end{array}$

TABLE $V . b$

\begin{tabular}{ll|l|ll}
$\mathrm{FeSO}_{+}$ & $\mathrm{I} . \mathrm{O}$ & 0.7 & 0.4 & 0.0 \\
$\mathrm{As}$ & 7.95 & 5.75 & 3.35 & 0.0
\end{tabular}

It will be seen that as the concentration of the acid increases in the proportion $I: I .5: 2$, the value of $k_{2}$ increases in the proportion $I: 2.4: 4$, that is, the rate is proportional to the square of the concentration of the acid; in other words, the reaction is of the second order with respect to the acid.

\section{Influence of the bichromate on the rate}

Comparing Tables III., VI., VII., it appears that when the concentration of the bichromate increases in the proportion I: $2: 3$, the rate $k_{2}$ increases in the proportion $I: 3.2: 7$, that is, 
the rate is proportional to the I. 7 th or 1.8 th power of the concentration of the bichromate.

TABLE VI. $a$

$\mathrm{H}_{2} \mathrm{SO}_{4}$ I0O cc, $\mathrm{K}_{2} \mathrm{Cr}_{2} \mathrm{O}_{7} 200 \mathrm{cc}$, Ox. prod. $50 \mathrm{cc}, \mathrm{FeSO}_{4}$ I cc,

Vol. $600 \mathrm{cc}$.

\begin{tabular}{lllll}
\hline$\theta$ & 0.0 & 1.0 & 2.0 & 4.0 \\
As & 4.25 & 2.55 & 1.90 & I. IO \\
A $-x$ & 1.0 & 0.6 & 0.44 & 0.26 \\
$k_{2}$ & - & 0.67 & 0.63 & $0.7 \mathrm{I}$
\end{tabular}

TABLE VI. $b$

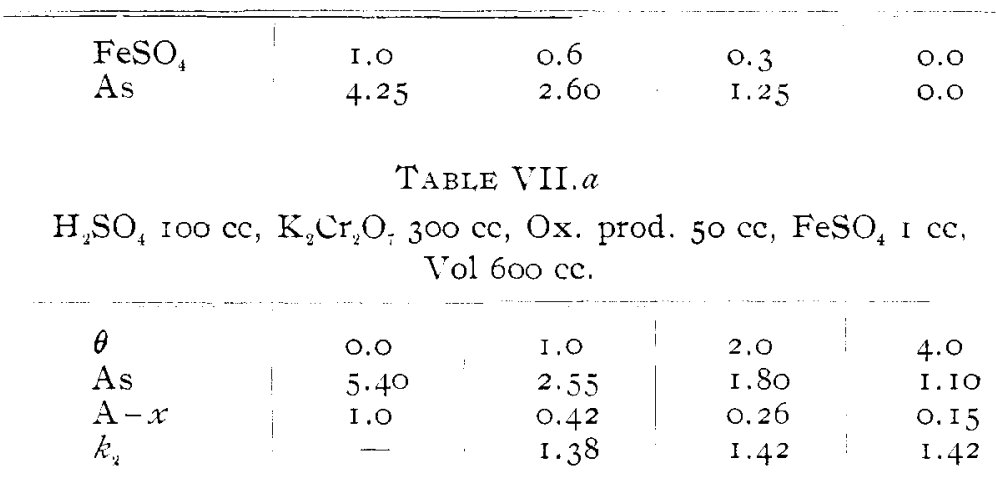

TABLE VII. $b$

\begin{tabular}{l|llllll} 
& & & & \\
$\mathrm{FeSO}_{4}$ & 1.0 & 0.4 & 0.3 & 0.2 & 0.0 \\
$\mathrm{As}$ & 5.40 & 2.70 & 2.05 & 1.45 & 0.0
\end{tabular}

One is tempted to ascribe the difference between I. 8 and the round number 2, to "change of dissociation"; in the present case, however, this explanation seems hardly available. The solutions in which the rates were measured contained but 0.000138 gram-1nol potassinm bichronnate per liter (or two and three times that amount, respectively); and as chromic acid has a place among the strongest acids, ${ }^{{ }^{2}}$ it must be regarded as com-

${ }^{1}$ Zeit. phys. Chem, 2, 78 (1888). 
pletely dissociated at such dilutions, whereas a simple calculation $^{I}$ (based on the assumptions: that the chromic acid dissociates according to the equation $\mathrm{H}+\overline{\mathrm{Cr}_{2}} \overline{\mathrm{O}} 7=\mathrm{HCr}_{2} \mathrm{O}_{7}$; that the sulphuric acid is totally dissociated; and that the reactions between the ions obey the mass law) leads to the conclusion that in a solution of chromic acid containing 0.000 r 38 gram-mol per liter, more than 20 percent of the acid must be in the form $\overrightarrow{\mathrm{HCr}_{2}} \mathrm{O}$, if the difference between $\mathrm{I} .8$ and 2.0 is to be ascribed to a difference between the dissociation of the chromic acid in the experiments of Table II. and those of Table VII.

A similar calculation shows that if the discrepancy be due to dissociation, then in the presence of a larger amount of acid the ratio of the rates should more nearly approach the square of the ratios of the amounts of bichromate used. A comparison of Table VIII. with Table IV. shows that the reverse is the case.

TABLE VIII. $a$

$\mathrm{H}_{2} \mathrm{SO}_{+} \mathrm{I} 50 \mathrm{cc}, \mathrm{K}_{2} \mathrm{Cr}_{2} \mathrm{O}_{i} 200 \mathrm{cc}, \mathrm{Ox}$. prod. $50 \mathrm{cc}, \mathrm{FeSO}_{4}$ I cc,

Vol. $600 \mathrm{cc}$.

\begin{tabular}{l|lll|l}
$\theta$ & 0.0 & 1.0 & 2.0 & 4.0 \\
As & 7.25 & 3.69 & 2.40 & 1.55 \\
A $-x$ & 1.0 & 0.46 & 0.30 & 0.19 \\
$k_{2}$ & - & 1.17 & 1.17 & 1.07
\end{tabular}

TABIE VIII. $b$

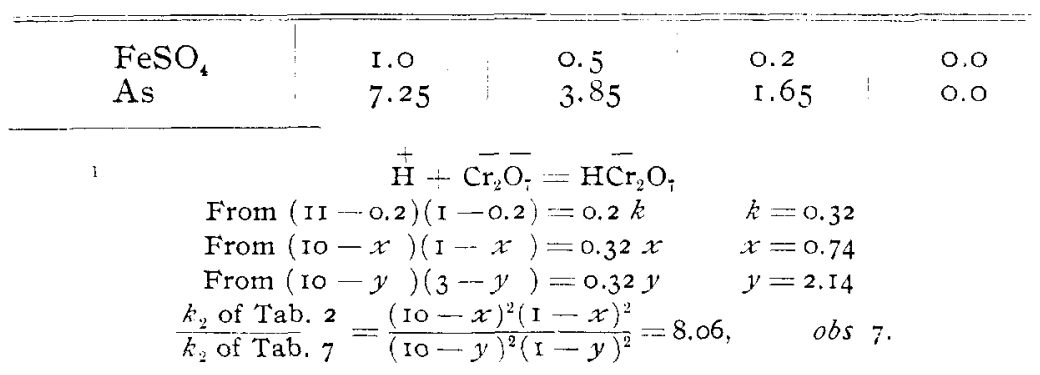


In order to ascertain whether the potassium sulphate formed by the action of sulphuric acid on the bichromate had any noticeable retarding effect, I carried out a series of experiments in which $20 \mathrm{Cc}$ of $F / 2 \mathrm{O}^{\mathrm{I}}$ solution of potassium sulphate was added to the reacting mixture. The effect on the rate, if any, fell within the errors of observation.

Further experiments are needed before a satisfactory explanation of these numbers can be arrived at.

\section{Influence of the products of oxidation on the rate}

The great retarding influence which the products of oxidation exert on the rate may be seen by comparing the experiments of Table IX. (no oxidation product present initially) with those of Table VI. In the absence of oxidation product (except such as was formed during the course of the measurements) twothirds of the ferrous salt is oxidized in fifteen seconds; if however the product of oxidation of $5 \mathrm{cc}$ ferrous sulphate be added at the beginning of the experiment, nearly two minutes are required to bring about the same amonnt of oxidation.

The rapid decrease of the "constant" $k_{2}$ of Table IX. is therefore not surprising.

TABLE IX. $a$

$\mathrm{H}_{2} \mathrm{SO}_{+} 100 \mathrm{cc}, \mathrm{K}_{2} \mathrm{Cr}_{2} \mathrm{O}_{7} 200 \mathrm{cc}, \mathrm{Ox}$. prod. none, $\mathrm{FeSO}_{4} \mathrm{I} \mathrm{cc}$, Vol. $600 \mathrm{cc}$.

$\begin{array}{lllllll}\theta & 0.0 & 0.25 & 0.5 & 1.0 & 2.0 & 4.0 \\ \text { As } & 6.40 & 3.05 & 2.30 & 1.65 & 1.05 & 0.60 \\ \text { A }-x & 1.0 & 0.42 & 0.3 & 0.2 & 0.12 & 0.07 \\ k_{z} & - & 5.6 & 4.66 & 4.0 & 3.65 & 3.4 \\ \text { C } & - & 5.6 & 3.7 & 3.3 & 3.3 & 3.0 \\ \text { Average } x & - & 0.29 & 0.64 & 0.75 & 0.84 & 0.90\end{array}$

TAPIE IX.b

$\begin{array}{lllllll}\mathrm{FeSO} & 1.0 & 0.8 & 0.6 & 0.4 & 0.2 & 0.0 \\ \mathrm{As} & 6.40 & 5.35 & 4.20 & 2.95 & 1.65 & 0.0\end{array}$

' One gram-Formula weight in twenty liters. 
A number of experiments carried ont with addition of potassium sulphate, chrome alum, and iron alum respectively, to the reacting mixture, slowed that the retardation was due almost entirely to the ferric salt present in the product of oxidation.

Under $C$ in Table IX. are given the values of $k_{z}$ calculated from each successive pair of values of $\theta$ and $A-r$; these numbers, although very much affected by the errors of observation, show that relatively the most effect is produced by the first addition of fertic salt. From the data collected in Table X. it appears that the same is true for larger additions of the ferric salt as well.

TABLE X.

$\begin{array}{lllll}\text { Ox prod. } & 0.29 & 0.9 & 5.0 & 20.0 \\ k^{\prime} & 5.6 & 3.0 & 0.68 & 0+^{2} \\ \text { Table } & \text { IX. } & \text { IX. } & \text { II. } & \text { XI. }\end{array}$

TABLE XI.

$\mathrm{H}_{2} \mathrm{SO}_{4} 100 \mathrm{cc}, \mathrm{K}_{2} \mathrm{Cr}_{2} \mathrm{O}, 200 \mathrm{cc}$, Ox. prod, $200 \mathrm{cc}, \mathrm{FeSO}_{4} \mathrm{lcc}$,

Vol. $600 \mathrm{cc}$.

$\begin{array}{llllllll}\theta & 0.0 & 0.5 & 1.0 & 2.0 & 3.0 & 6.0 \\ \text { As } & 4.10 & 3.40 & 3.00 & 2.15 & 1.80 & 1.20 \\ A-r & 1.00 & 0.83 & 0.73 & 0.52 & 0.44 & 0.29 \\ h_{2} & - & 0.40 & 0.37 & 0.46 & 0.42 & 0.41\end{array}$

These facts might be accounted for - at least qualitatively - by assuming that on addition of ferric salt, part of the ferrous sulphate is converted into a ferroso-ferric compound, thus lowering the concentration of the ferrous salt in the solution, and consequently diminishing the rate. The relatively great effect produced by the first half cc of ferric salt is in harmony with this hypothesis.

\section{Conclusion}

(I) An analytical method has been derised for determining ferrous iron in the presence of ferric salts and chromic acid. 
(2) The rate of oxidation of ferrous sulphate in solutions containing potassium bichromate and sulphuric acid is proportional to the second power of the concentration of ferrous salt, and to the second power of that of the acid. The order of the reaction with respect to the bichromate is variable. The oxidation is much retarded by the presence of ferric salts.

Further experiments are in progress.

In conclusion I wish to express my thanks to Prof. W. Lash Miller, for the interest he has displayed in this research.

University of Toronto, July, 1902

TABLE OF CONTENTS

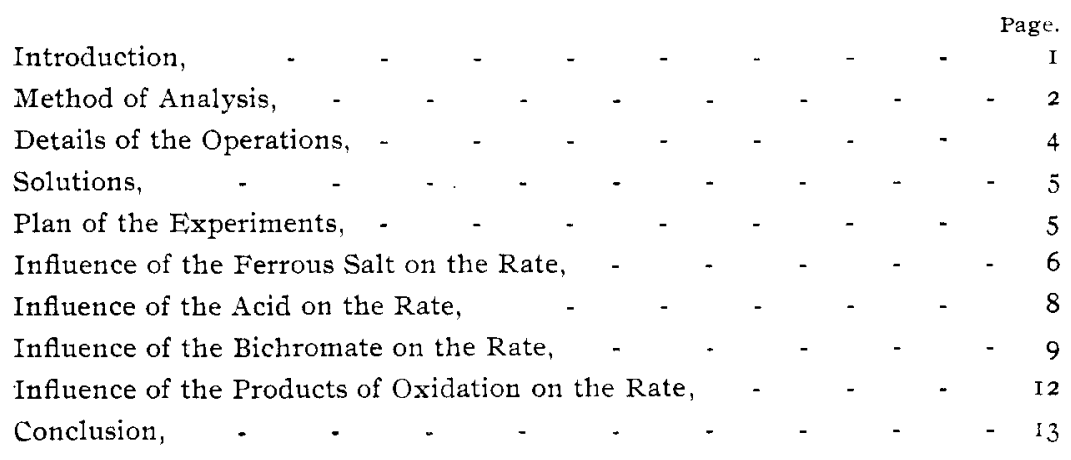

